\title{
Development of Internal Dose Assessment Procedure for Workers in Industries Using Raw Materials Containing Naturally Occurring Radioactive Materials
}

\author{
Cheol Kyu Choi', Yong Geon Kim', Seung Woo Ji', Boncheol Koo², Byung Uck Chang², Kwang Pyo Kim ${ }^{1, *}$ \\ ${ }^{1}$ College of Engineering, Kyung Hee University, Yongin; ${ }^{2}$ Korea Institute of Nuclear Safety, Daejeon, Korea
}

\section{Technical Paper}

Received April 15, 2016

Revision June 14, 2016

Accepted July 12, 2016

Corresponding author: Kwang Pyo Kim

Kyung Hee University, 1732, Deokyoungdaero, Giheung-gu, Yongin 17104, Korea

Tel: +82-10-4030-7067

Fax: +82-31-273-3592

E-mail:kpkim@khu.ac.kr

This is an Open-Access article distributed under the terms of the Creative Commons Attribution NonCommercial License (http://creativecommons.org/ licenses/by-nc/4.0) which permits unrestricted noncommercial use, distribution, and reproduction in any medium, provided the original work is properly cited.

Copyright $\odot$ 2016 The Korean Association for Radiation Protection

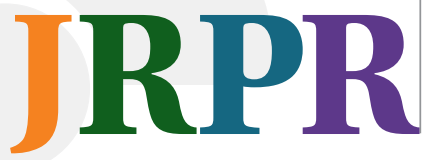

Background: It is necessary to assess radiation dose to workers due to inhalation of airborne particulates containing naturally occurring radioactive materials (NORM) to ensure radiological safety required by the Natural Radiation Safety Management Act. The objective of this study is to develop an internal dose assessment procedure for workers at industries using raw materials containing natural radionuclides.

Materials and Methods: The dose assessment procedure was developed based on harmonization, accuracy, and proportionality. The procedure includes determination of dose assessment necessity, preliminary dose estimation, airborne particulate sampling and characterization, and detailed assessment of radiation dose.

Results and Discussion: The developed dose assessment procedure is as follows. Radioactivity concentration criteria to determine dose assessment necessity are $10 \mathrm{~Bq} \cdot \mathrm{g}^{-1}$ for ${ }^{40} \mathrm{~K}$ and $1 \mathrm{~Bq} \cdot \mathrm{g}^{-1}$ for the other natural radionuclides. The preliminary dose estimation is performed using annual limit on intake (ALI). The estimated doses are classified into 3 groups ( $<0.1 \mathrm{mSv}, 0.1-0.3 \mathrm{mSv}$, and $>0.3 \mathrm{mSv}$ ). Air sampling methods are determined based on the dose estimates. Detailed dose assessment is performed using air sampling and particulate characterization. The final dose results are classified into 4 different levels ( $<0.1 \mathrm{mSv}, 0.1-0.3 \mathrm{mSv}, 0.3-1 \mathrm{mSv}$, and $>1 \mathrm{mSv}$ ). Proper radiation protection measures are suggested according to the dose level. The developed dose assessment procedure was applied for NORM industries in Korea, including coal combustion, phosphate processing, and monazite handing facilities.

Conclusion: The developed procedure provides consistent dose assessment results and contributes to the establishment of optimization of radiological protection in NORM industries.

Keywords: Naturally occurring radioactive material (NORM), Internal dose, Dose assessment procedure, Air sampling

\section{Introduction}

The Natural Radiation Safety Management Act (NRSMA), enforced in 2012, is a national-level management system concerned with widespread circulation of naturally occurring radioactive material (NORM) in people's everyday lives (Natural Radiation Safety Management Act, Legislation 10908). NRSMA promotes public safety and quality of life by protecting citizen health and the environment through providing safety management regulations for radiation. The most basic point of enforcing the NRSMA is a dose assessment procedure for workers regarding raw materials, process by-products, and processed goods containing naturally occurring radioactive nuclides. Work- 
ers who are part of industries that use materials containing naturally occurring radioactive nuclides may have experienced internal exposure to radiation due to inhalation of airborne particulates.

In the case of South Korea, raw materials containing naturally occurring radioactive nuclides, such as monazite, phosphate rock, and coal, are utilized in various industries, such as manufacturing processed goods and producing electric power. However, no detailed guidelines have been proposed regarding the selection method of industries that need radiological safety assessments and a dose assessment method for those industries. In the case of foreign countries, the radiological danger of handling materials containing a large quantity of naturally occurring radioactive nuclides has been recognized and research has been conducted on the radiological effects of the materials. Out of the facilities that handle materials containing the International Atomic Energy Agency (IAEA) proposed 11 fields that must primarily consider regulation, and based on this, it conducted a radiological safety assessment of raw materials like zircon and minerals containing thorium [1-4]. The European Commission (EC) conducted an internal dose assessment for workers through surveillance of the workplace [5]. Moreover, dose assessments have been carried out for various industries, such as industries that deal with phosphate rock and coal [6-8].

So far, the procedures for internal dose assessments conducted on industries that deal with raw materials containing naturally occurring radioactive nuclides have differed depending on the study. The international community recognized this issue and the need to develop guidelines for internal dose assessment. The European Radiation Dosimetry Group (EURADOS) published guidelines for internal dose assessment through the IDEAS project [9]. The Nuclear Regulatory Commission (NRC) published a regulatory guide on the collection of airborne particulates for internal dose assessment [10]. However, the guidelines for internal dose assessment were developed for workers in the radiation field, so there are limitations to applying the guidelines to workers who are in general industries that handle raw materials containing naturally occurring radioactive nuclides. Moreover, the guidelines do not stipulate which strategy, out of various surveillance strategies for the workplace, must be selected in order to carry out the assessment. South Korea has enforced the NRSMA to secure radiological safety for workers in industries that handle raw materials containing naturally occurring radioactive nuclides; therefore, an internal dose as- sessment procedure must be developed for workers in those industries.

This study developed an internal dose assessment procedure for workers in industries that handle raw materials containing naturally occurring radioactive nuclides. This procedure was developed based on the radioactivity concentration in materials, the annual limit of intake (ALI), and airborne particulate sampling. By applying the developed procedure to South Korean industries, the study then presented application methods for the assessment procedure.

\section{Materials and Methods}

The internal dose assessment procedure was developed based on the three basic principles of IDEAS, the internal dose assessment project conducted by EURADOS: harmonization, accuracy, and proportionality. Harmonization means that if the monitored data is the same, a similar result will be attained even if the evaluator changes. Accuracy means attaining the best result from the usable data. Finally, proportionality means that the time and effort exerted during the dose assessment are proportional to the dose. Based on these principles, the internal dose assessment procedure in this study was composed of determining the need for dose assessment, preliminary dose estimation, determining the need for particulate sampling, airborne particulate sampling and characterization, and detailed assessment of radiation dose.

In this study, the need for dose assessment was determined based on radiation concentration and the total annual amount of radiation handled. According to the IAEA, exposure to radiation due to NORM in a general setting is not included in the regulations. However, if a large amount is handled by industries, the radiation exposure increases for workers, which could make the case subject to regulation for radiation protection. The radiation source that could become subject to regulation is classified according to radiation concentration and the total amount of radiation, and if less than the standard value, the IAEA stipulates that there is no need for regulation [11].

If it is determined that a dose assessment is needed, a preliminary dose estimation is conducted. Based on the results of the estimation, the need for airborne particulate sampling is determined. The preliminary dose estimation is performed using the annual limit on intake of the ${ }^{238} \mathrm{U}$ decay series, ${ }^{232} \mathrm{Th}$ decay series, and the ${ }^{40} \mathrm{~K}$ nuclide [12]. Out of the ${ }^{238} \mathrm{U}$ decay 

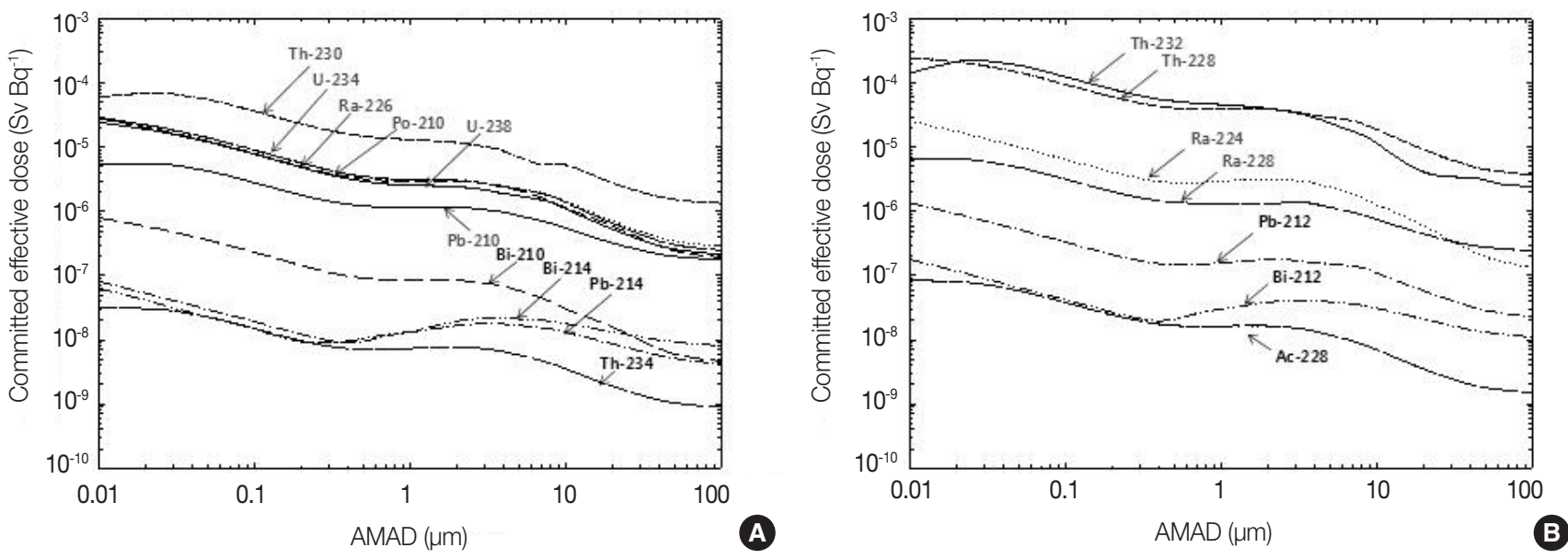

Fig. 1. Committed effective dose due to inhalation of airborne particulates by particulate size and radionuclide type: $(A)^{238} \mathrm{U}$ decay series, $(B)$ ${ }^{232}$ Th decay series.

series and ${ }^{232} \mathrm{Th}$ decay series nuclides, some nuclides have a marginal level of contribution to radiation dose. Therefore, these nuclides were excluded in this assessment procedure. The following nuclides were considered in the assessment of radiation dose due to the inhalation of airborne particulates: ${ }^{230} \mathrm{Th},{ }^{234} \mathrm{U},{ }^{226} \mathrm{Ra},{ }^{210} \mathrm{Po},{ }^{238} \mathrm{U}$, ${ }^{210} \mathrm{~Pb}$ out of the ${ }^{238} \mathrm{U}$ decay series, and ${ }^{232} \mathrm{Th}$, ${ }^{228} \mathrm{Th},{ }^{228} \mathrm{Ra},{ }^{224} \mathrm{Ra}$ out of the ${ }^{232} \mathrm{Th}$ decay series. Figure 1 presents the shift factors of the committed effective dose due to inhalation of airborne particulates that contain ${ }^{238} \mathrm{U}$ decay series and ${ }^{232} \mathrm{Th}$ decay series nuclides.

The internal dose assessment for workers who inhale radionuclides while handling raw materials containing naturally occurring radioactive nuclides was developed based on airborne particulate sampling. According to the study conducted by the European Commission, compared to biological testing, airborne particulate sampling was proposed as the best method to assess radiation dose and to provide optimized data on radiation protection [5]. The internal dose assessment was carried out by conducting airborne particulate sampling based on the estimated radiation dose, which was categorized into three groups using ALI (less than $0.1 \mathrm{mSv}$, 0.1-0.3 mSv, greater than $0.3 \mathrm{mSv}$ ). The airborne particulate samplers considered in this study were the high-volume sampler, personal air sampler, and cascade impactor. In addition, the internal dose assessment results were divided into level 0 (less than $0.1 \mathrm{mSv}$ ), level 1 (0.1-0.3 mSv), level 2 (0.3-1 $\mathrm{mSv}$ ), and level 3 (greater than $1 \mathrm{mSv}$ ) in order to recommend appropriate radiation protection measures according to each level.

The final internal dose assessment procedure that was de- veloped applied the procedure to South Korean industries and proposed application methods of the assessment procedure. The target industries were industries that handled coal, phosphate rock, and monazite containing naturally occurring radioactive nuclides. For the internal dose assessment procedure of the target industries, the radioactivity concentration of raw materials and total amount of material handled annually were investigated through field studies, and based on this, the necessity of an internal dose assessment was determined according to the dose assessment procedure and conducted if needed.

\section{Results and Discussion}

Figure 2 presents the internal dose assessment procedure developed in this study. In the procedure proposed in this study, the assessment results of the internal dose to workers were divided into levels $0,1,2$, and 3 in order to optimize the time and effort required for protection measures according to assessment results.

\section{Determining the need for internal dose assessment}

The subjects of this assessment procedure were the raw materials regulated by the NRSMA. The raw materials defined in the Act are NORM, which contains ${ }^{235} \mathrm{U}$ series, ${ }^{238} \mathrm{U}$ series, ${ }^{232} \mathrm{Th}$ series, or ${ }^{40} \mathrm{~K}$ that exceed a certain radioactivity concentration and total radioactivity. The standard radioactivity concentration for ${ }^{40} \mathrm{~K}$ nuclide is $1 \mathrm{~Bq} \cdot \mathrm{g}^{-1}$ and for ${ }^{235} \mathrm{U}$ series, ${ }^{238} \mathrm{U}$ series, and ${ }^{232} \mathrm{Th}$ series nuclides, it is $0.1 \mathrm{~Bq} \cdot \mathrm{g}^{-1}$. The standard total radioactivity is when the naturally occurring 


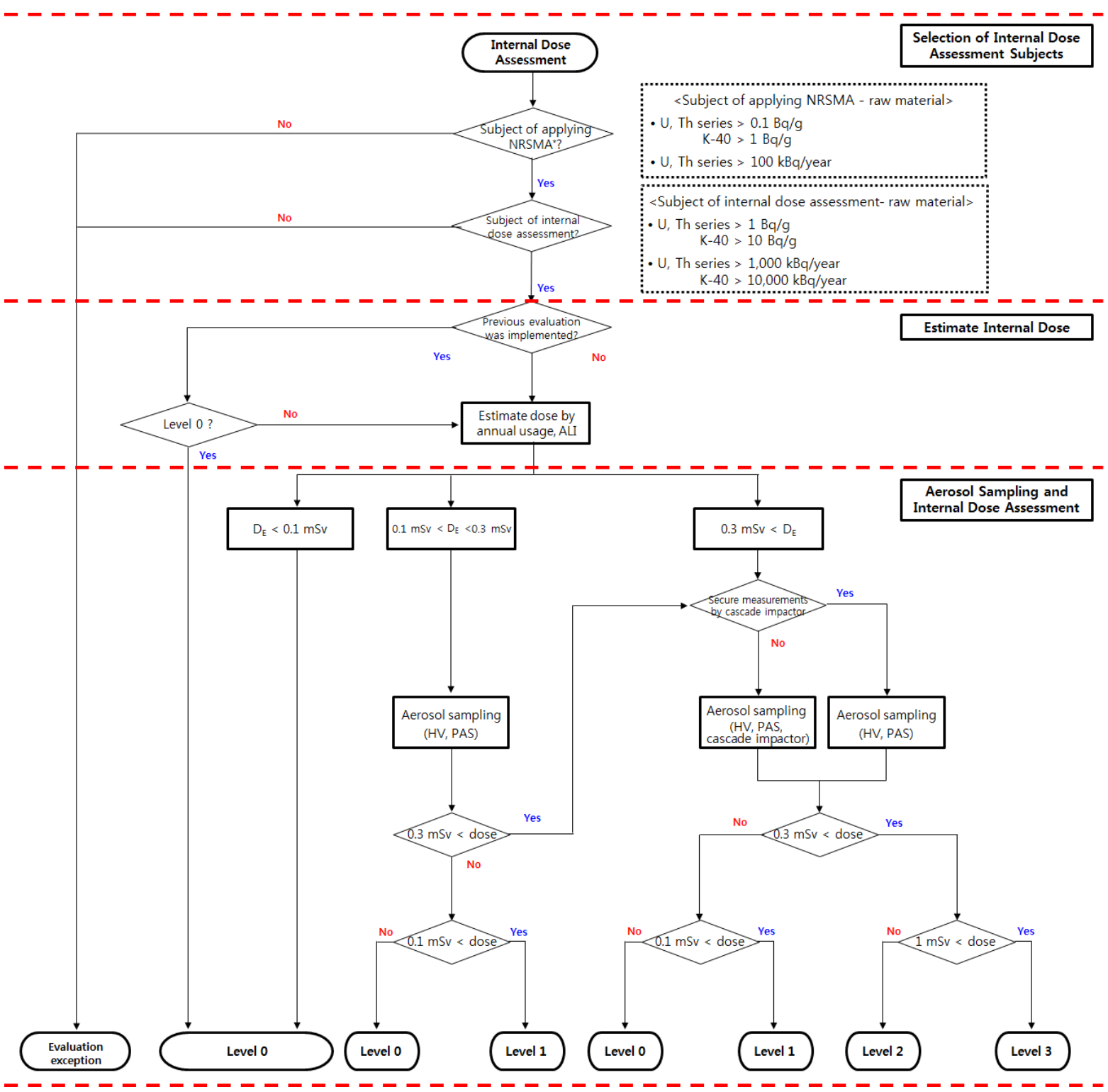

Fig. 2. Internal dose assessment procedure for workers in industries using raw materials containing naturally occurring radioactive materials. NRSMA, Natural Radiation Safety Management Act.

radioactive nuclides contained in the raw materials amounts to $100 \mathrm{kBq}$ handled annually. Therefore, materials that did not exceed the aforementioned radioactivity concentration and total radioactivity handled annually were excluded from the assessment procedure.

The IAEA proposed the radioactivity concentration of naturally occurring radioactive nuclides $\left(10 \mathrm{~Bq} \cdot \mathrm{g}^{-1}\right.$ for the ${ }^{40} \mathrm{~K}$ nuclide, and $1 \mathrm{~Bq} \cdot \mathrm{g}^{-1}$ for ${ }^{235} \mathrm{U}$ series, ${ }^{238} \mathrm{U}$ series, and ${ }^{232} \mathrm{Th}$ series nuclides) and the total radioactivity handled annually $\left(10,000 \mathrm{kBq} \cdot \mathrm{y}^{-1}\right.$ for the ${ }^{40} \mathrm{~K}$ nuclide and $1,000 \mathrm{kBq} \cdot \mathrm{y}^{-1}$ for ${ }^{235} \mathrm{U}$ series, ${ }^{238} \mathrm{U}$ series, and ${ }^{232} \mathrm{Th}$ series nuclides) that are not applicable to the regulations for radiation protection [11].
Therefore, if the radiation concentration and total radioactivity of the raw materials did not exceed standards, the materials were excluded from the assessment procedure.

\section{Preliminary internal dose estimation}

If there was a previous record of conducting an internal dose assessment before the preliminary internal dose estimation, the assessment results were checked. If the past assessment result was less than $0.1 \mathrm{mSv}$ (level 0), the internal dose was not re-assessed.

If there was no previous record of assessing internal dose, or if the previous assessment result was greater than level 1, 
Table 1. Annual Limit on Intake (ALI) for ${ }^{238} \mathrm{U}$ Series, ${ }^{232} \mathrm{Th}$ Series, and ${ }^{40} \mathrm{~K}$ by Absorption Type

\begin{tabular}{lcccc}
\hline \multirow{2}{*}{ Radionuclides } & & \multicolumn{3}{c}{ Annual limit on intake $(\mathrm{Bq})$} \\
\cline { 3 - 5 } & & Type $\mathrm{F}$ & \multicolumn{1}{c}{ Type M } & Type S \\
\hline${ }^{238} \mathrm{U}$ decay series & ${ }^{238} \mathrm{U}$ & 30,000 & $10,000^{*}$ & 4,000 \\
& ${ }^{234} \mathrm{U}$ & 30,000 & $10,000^{*}$ & 3,000 \\
& ${ }^{230} \mathrm{Th}$ & - & - & $3,000^{*}$ \\
& ${ }^{226} \mathrm{Ra}$ & - & $9,000^{*}$ & - \\
& ${ }^{210} \mathrm{~Pb}$ & 20,000 & $20,000^{*}$ & - \\
& ${ }^{210} \mathrm{Po}$ & 30,000 & $9,000^{*}$ & - \\
${ }^{232} \mathrm{Th}$ decay series & ${ }^{232} \mathrm{Th}$ & - & 700 & $2,000^{*}$ \\
& ${ }^{228} \mathrm{Ra}$ & - & $10,000^{*}$ & - \\
& ${ }^{228} \mathrm{Th}$ & - & 900 & $600^{*}$ \\
& ${ }^{224} \mathrm{Ra}$ & - & $8,000^{*}$ & - \\
${ }^{40} \mathrm{~K}$ & & $7,000,000$ & & \\
\hline
\end{tabular}

*ICRP reference absorption types.

the internal dose was estimated using the total amount of material handled annually and ALI. Table 1 presents the ALI of the key nuclides selected in this study (Standards on radiation protection, Nuclear Safety Commission announcement 2014-34). For absorption types, the study applied the basic absorption types presented by the International Commission on Radiological Protection (ICRP) [14].

Regulatory guide 8.25 of the US Nuclear Regulatory Commission (NRC) suggested that experience had shown that worker intakes were unlikely to exceed one one-millionth of the material being handled or processed. Furthermore, any worker who handled or processed unsealed or loose radioactive materials in quantities that during a year would total more than 10,000 times the ALI for inhalation should evaluate the need for air sampling [10]. When considering the amount of particulates inhaled depended on the amount of materials handled, $0.2 \mathrm{mSv}$ was the dose that was spawned when total radioactivity handled annually was 10,000 times the ALI. IDEAS suggested $0.1 \mathrm{mSv}$ as the standard for determining the need for internal dose assessment. In order to carry out a conservative assessment, this study set the standard as $0.1 \mathrm{mSv}$, the assessment standard of the IDEAS. To meet this standard, rather than applying the ' 10,000 times greater than the ALI' rule set forth by the IAEA, this study proposes that airborne particulate sampling is needed if total radioactivity handled annually is 5,000 times greater than the ALI. If more than one type of radionuclide is contained, the value obtained from dividing the ALI by the sum of each nuclide usage is assessed as to whether or not it is 5,000 times greater than the ALI. If the radiation concentration and total amount of materials handled annually dose is known, the
Table 2. Release Fraction, Confinement Factor, and Dispersibility for Internal Dose Estimation

\begin{tabular}{lll}
\hline Factor & \multicolumn{1}{c}{ Classification detail } & Value \\
\hline Release fraction & Gases or volatile materials & 1.0 \\
& Nonvolatile powders & 0.01 \\
& Solids (uranium fuel pellets, cobalt metal) & 0.001 \\
& Liquids & 0.01 \\
& Encapsulated materials & 0 \\
Confinement factor & Handled in a glovebox & 0.01 \\
& Handled in a well ventilated hood & 0.1 \\
& Handled in an open work area & 1 \\
Dispersibility & Cutting, grinding, heating, or chemical & 10 \\
& reactions &
\end{tabular}

formula to determine the need for particulate sampling is as follows:

$$
\sum_{\mathrm{i}} \frac{\mathrm{I}_{\mathrm{i}} \times \mathrm{U}}{\mathrm{ALI}_{\mathrm{i}}} \geq 5,000
$$

$\mathrm{I}_{\mathrm{i}}$ is the radioactivity concentration of nuclide $\mathrm{i}, \mathrm{U}$ is the total amount of materials handled annually, and ALI is the annual limit on intake of the nuclide i. If after the computation, it is determined that an airborne particulate sampling is needed, the internal dose is estimated using the ALI of each nuclide and the potential intake. This is calculated using the release fraction (in order to reflect workplace characteristics), confinement factor, and index of dispersion. The formulas below calculate the potential intake and estimated internal dose.

$$
\begin{aligned}
& \mathrm{I}_{\mathrm{p}, \mathrm{i}}=\mathrm{Q}_{\mathrm{i}} \times 10^{-6} \times \mathrm{R} \times \mathrm{C} \times \mathrm{D} \\
& \mathrm{D}_{\mathrm{E}}=\sum_{\mathrm{i}} \frac{\mathrm{I}_{\mathrm{p}, \mathrm{i}}}{\mathrm{ALI}_{\mathrm{i}}} \times 20 \mathrm{mSv}
\end{aligned}
$$

$\mathrm{I}_{\mathrm{p}}, \mathrm{I}$ is the potential intake of nuclide $\mathrm{i}, \mathrm{Q}_{\mathrm{i}}$ is the total radioactivity nuclide $i$ within the material, $\mathrm{R}$ is the release fraction, $\mathrm{C}$ is the confinement factor, $\mathrm{D}$ is dispersibility, and is $\mathrm{D}_{\mathrm{E}}$ the dose estimate. The total radioactivity can be identified through an investigation of the target industry. The release fraction can be determined by the type of material the industry handles, and this is set forth in 10CFR 30.72 of the NRC. The confinement factor is used to consider the degree of dust leakage at the location where materials are handled. The factor is closer to 1 if the materials are handled in an open area. The dispersibility is a factor that increases the potential intake with operations like cutting and grinding, during which a lot of dust is released. If any such operation occurs, a dispersibility factor of 10 is applied. Table 2 presents the factors that must be considered for estimation of radiation dose. 
Table 3. Method of Airborne Particulates Sampling and Internal Dose Assessment Based on Estimated Radiation Dose

\begin{tabular}{ll}
\hline Estimated radiation dose $(\mathrm{mSv})$ & \multicolumn{1}{c}{ Method of airborne particulates sampling and internal dose assessment } \\
\hline$<0.1$ & - Air sampling and dose assessment are generally not necessary \\
$0.1-0.3$ & - Air samplers \\
& - PAS or Hi-vol \\
& - Air sampling frequency \\
& - PAS: Monthly or quarterly sampling by estimator decision \\
& - Hi-vol: Monthly or quarterly sampling by estimator decision \\
& - Performing temporary air sampling when working environment was rapidly changing \\
& - Internal dose assessment method \\
& - Using particulate concentration of air sampler and radioactivity concentration \\
& - Using ICRP reference value for particulate properties \\
& - Air samplers \\
& - PAS or Hi-vol \\
- Cascade impactor \\
- Air sampling frequency \\
- PAS: Monthly or quarterly sampling by estimator decision \\
- Hi-vol: Monthly or quarterly sampling by estimator decision \\
- Cascade impactor: Yearly sampling by estimator decision \\
- Performing temporary air sampling when working environment was rapidly changing \\
- Internal dose assessment method \\
- Using particulate concentration of air sampler and radioactivity concentration \\
- Using site-specific information on particulate properties by cascade impactor \\
- Credit may be taken for protection factors if a respiratory protection is in place
\end{tabular}

PAS, Personal air sampler; Hi-vol, High volume air sampler.

\section{Airborne particulate sampling and internal dose assessment}

Table 3 presents the method of airborne particulate sampling and internal dose assessment based on the estimated radiation dose. Methods for airborne particulate sampling can be divided into consecutive sampling and random sampling. Consecutive sampling is done by continuously monitoring the workplace, and random sampling is done by collecting airborne particulates at a particular moment. The random sampling method is appropriate for workplaces that are generally known to be stable. In general, it is rare that workplaces for industries that handle materials containing naturally occurring radioactive nuclides will change suddenly, since the same tasks are repeated within the facility. Therefore, random sampling was established as the airborne particulate sampling method for this procedure, and following the NRC recommendation, the sampling cycle was set at a monthly or quarterly basis [10]. However, if the type of material handled changes, the workplace must be re-assessed by carrying out a particulate sampling as soon as possible, regardless of the period of sampling set.

In order to optimize the time spent on internal dose assessment, different methods were used for the airborne particulate sampling and dose assessment, depending on the estimated radiation dose. The annual radiation dose due to potential intake was divided into three intervals: less than 0.1
$\mathrm{mSv}, 0.1-0.3 \mathrm{mSv}$, and $0.3 \mathrm{mSv}$. Based on the IAEA classification criteria for situations of radiation exposure, $0.3 \mathrm{mSv}$ was set as the standard. The IAEA classifies situations of radiation exposure due to naturally occurring radioactive nuclides as 'planned exposure situations' if the radioactivity concentration of the ${ }^{238} \mathrm{U}$ decay series and ${ }^{232} \mathrm{Th}$ decay series exceeds 1 $\mathrm{Bq} \cdot \mathrm{g}^{-1}$ or if the radiation concentration of ${ }^{40} \mathrm{~K}$ exceeds $10 \mathrm{~Bq} \cdot \mathrm{g}^{-1}$ [15]. In the beginning stages of the procedure in this study, the radioactivity concentration of targeted materials was set as greater than $1 \mathrm{~Bq} \cdot \mathrm{g}^{-1}$ for the ${ }^{238} \mathrm{U}$ decay series and ${ }^{232} \mathrm{Th}$ decay series, and greater than $10 \mathrm{~Bq} \cdot \mathrm{g}^{-1}$ for the ${ }^{40} \mathrm{~K}$ nuclide. Therefore, it is correct to classify the radiation exposure situations of the industries that handle NORM needed for the internal dose assessment as 'planned exposure situations' of radiation exposure. In the planned exposure situations, a dose limit value concept is used in connection with the 'aslow-as-reasonably-possible' (ALARP) principle, in order to limit individual dose. The dose limit value indicates the basic protection level, and must always be lower than the target dose limit. The ICRP recommends that in cases of individual exposure, the appropriate dose limit value should be less than $1 \mathrm{mSv}$ and should not be greater than approximately 0.3 $\mathrm{mSv}$ [16]. Therefore, this procedure sets $0.3 \mathrm{mSv}$ as the standard estimated radiation dose. If the estimated dose is less than $0.1 \mathrm{mSv}$, there is no need for a dose assessment. Such cases are classified as level 0 , and dose assessments are not 
conducted.

In cases where the annual estimated dose due to potential intake is between 0.1 and $0.3 \mathrm{mSv}$, an internal dose assessment using particulate sampling is needed because there is a possibility that the dose will exceed $0.3 \mathrm{mSv}$, the dose limit value. For this estimated dose range, the concentration of airborne particulates can be analyzed using a high-volume sampler or a personal air sampler, and an internal dose assessment can be conducted using the base values set forth by the ICRP for particulate characteristics.

In cases where the annual estimated dose due to potential intake is greater than $0.3 \mathrm{mSv}$, protection from the radiation source has not been optimized. Therefore, additional measures are needed to manage exposure to radiation for workers and to lower the dose level. In order to do this, an internal dose assessment must be conducted through airborne particulate sampling that reflects the characteristics of the particulates. Airborne particulate sampling can be conducted using a high-volume sampler or a personal air sampler. In addition, because this estimated radiation dose range exceeds the dose limit value and may exceed $1 \mathrm{mSv}$, the dose limit for an individual, the internal dose assessment must be carried out using a cascade impactor in order to analyze particulate characteristics that have a great influence on the internal dose, such as the size, density, and shape of the particulates. The shape of the particulate defines the aerodynamic and thermodynamic relationships that affect the deposition and elimination of the particulate within the respiratory system. The shape of the particulate can be indicated by shape factors, and is defined by the ratio of the identical volume of the particulate against the resistance of the spherical particulate whose density is $1 \mathrm{~g} \cdot \mathrm{cm}^{-3}$ and the resistance of a particulate with an irregular form which has a settling velocity [17].

The location for installing samplers was set according to the NRC recommendations. Because a sampler is a tool that collects particulates that are inhaled through a person's respiratory system, it must be installed near the respiratory area. Therefore, a personal air sampler must be installed in a place that represents the breathing area, which is within approximately 30 centimeters of the worker's head, and a highvolume sampler must be installed where the respiratory system is located, approximately 1.5 meters above ground at a place where the worker is stationed $[10,12]$.

In cases of high-volume and personal air samplers, particulate sampling should be conducted monthly or quarterly, according to the NRC recommendations for random sam- pling cycles [10]. In the case of cascade impactors, particulate sampling should be measured more than once each year if there is no change that may affect the measurement results of the work environment, such as a change in process facilities or work methods. If there are distribution results for particulate sizes that were measured within a year in the aforementioned process, an internal dose assessment should be conducted using the distribution of particulate sizes that were measured previously. The workplace must be monitored by carrying out an additional temporary assessment if the work environment changes due to an increase in the total volume of raw materials, a change in the types of raw materials, or a change in specifications of process facilities.

The most rational way to carry out an internal dose assessment of a worker is to use a personal air sampler, which takes into account the worker's movement. However, there are limitations to carrying out an internal dose assessment by having the workers wear personal air samplers. To supplement this weakness, an internal dose assessment can be carried out with information about particulate characteristics that are collected using a high-volume sampler, which is used to monitor a space. However, if the area where the highvolume sampler is installed cannot represent the entire working process, there is a chance that the concentration of the air the workers breathe within the area could be greatly underestimated [18].

In order to secure radioactive safety for workers, appropriate protection measures are needed depending on the internal dose assessment results. In this procedure, radiation protection measures were recommended according to dose levels. Table 4 presents radiation protection measures depending on results of the internal dose assessment.

\section{Application of the internal dose assessment procedure}

The internal dose assessment procedure developed in this study for workers in industries that handle raw materials was applied to South Korean industries that handle coal combustion, phosphate rock, and monazite. Gamma spectrometry was used to analyze radioactivity concentration in order to determine the need for an internal dose assessment. Radioactivity concentration was measured for ${ }^{226} \mathrm{Ra}$ of the ${ }^{238} \mathrm{U}$ decay series, ${ }^{228} \mathrm{Ra}$ of the ${ }^{232} \mathrm{Th}$ decay series, and the ${ }^{40} \mathrm{~K}$ nuclide. Using a 1 liter Marinelli beaker, the sample was sealed for 30 days and after making the sample reach secular equilibrium, the HPGe detector (GC 3020, Canberra Inc., Meriden, CT) 
Table 4. Radiation Protection Management by Results of Exposure Dose Assessment

\begin{tabular}{ll}
\hline Level & \\
\hline Level 0 (Dose $<0.1 \mathrm{mSv})$ & $\cdot$ Radiation protection management by level \\
Level $1(0.1<$ Dose $<0.3 \mathrm{mSv})$ & $\cdot$ Maintain the present working status \\
Level $2(0.3<$ Dose $<1 \mathrm{mSv})$ & $\cdot$ Management of radiation dose for worker by monthly or quarterly dose assessment \\
& $\cdot$ Improvement of facilities and work process after monitoring \\
& $\cdot$ Adjust working hours \\
& $\cdot$ Provide proper protective devices \\
& $\cdot$ Management of radiation dose for worker by monthly or quarterly dose assessment \\
& $\cdot$ Prepare measures for exposure reduction by installation of shielding facilities \\
& $\cdot$ Establishment measures and implementation of improvement of facilities \\
& $\cdot$ Adjust working hours \\
& $\cdot$ Provide proper protective devices \\
& $\cdot$ Management of radiation dose for worker by monthly or quarterly dose assessment \\
\hline
\end{tabular}

was used to measure the radioactivity concentration. Using a particulate sampler, airborne particulate characteristics needed for the internal dose assessment were measured, such as activity median aerodynamic diameter (AMAD), geometric standard deviation (GSD), and shape factors.

\section{1) Coal combustion industries}

The coal combustion industries selected in this study imported approximately 4.3 million tons of coal annually for use. The radioactivity concentrations for the $238 \mathrm{U}$ decay series, 232Th decay series, and the ${ }^{40} \mathrm{~K}$ nuclide of the coal were $4.6 \mathrm{~Bq} \cdot \mathrm{kg}^{-1}, 3.3 \mathrm{~Bq} \cdot \mathrm{kg}^{-1}$, and $25 \mathrm{~Bq} \cdot \mathrm{kg}^{-1}$, respectively. After assessing the need for particulate sampling by examining the intake of materials used in the coal industry and the ALI of the key nuclides selected, the value was 5,000 times greater than the ALI. Therefore, using Formulas 1, 2, and 3, the preliminary internal dose was estimated. Because the scattered dust from handling coal is non-volatile dust, 0.01 was applied for the release fraction. Most of the process was conducted in an open-air storage yard, so the confinement factor was set as 1 . Moreover, dispersibility was not considered because there was no cutting or grinding in the coal yard, where the airborne particulate sampling was conducted.

Because the preliminary estimated dose exceeded 0.3 $\mathrm{mSv}$, a survey of the particulate characteristics was needed. In the worksite mentioned above, the surveyed AMAD was $4.3 \mu \mathrm{m}$, the GSD was 5.1 , the density was $1.4 \mathrm{~g} \cdot \mathrm{cm}^{-3}$, and the shape factor was 1 . Since workers wore dust masks while carrying out operations, this was taken into account when conducting the dose assessment. The resulting value of the internal dose assessment was less than $0.01 \mathrm{mSv}$, which corresponds to level 0 . Therefore, an additional internal dose assessment was not needed in the coal combustion indus- tries since internal exposure due to particulate inhalation had an insignificant effect. However, additional dose assessment is needed in cases where the work environment suddenly changes.

2) Industries that handle phosphate rock

The industries selected in this study that handle phosphate rock imported approximately 195,000 tons of phosphate rock annually for use. Analysis of radioactivity concentration showed that the ${ }^{238} \mathrm{U}$ decay series and ${ }^{232} \mathrm{Th}$ decay series nuclides did not achieve radioactive equilibrium. The radioactivity concentration was $850-1,100 \mathrm{~Bq} \cdot \mathrm{kg}^{-1}$ for the ${ }^{238} \mathrm{U}$ decay series, less than $0.72 \mathrm{~Bq} \cdot \mathrm{kg}^{-1}$ for the ${ }^{232} \mathrm{Th}$ decay series, and $62 \mathrm{~Bq} \cdot \mathrm{kg}^{-1}$ for the ${ }^{40} \mathrm{~K}$ nuclide. The need for particulate sampling was determined by examining the volume of phosphate rock materials and the ALI of the key nuclides was selected. The release fraction was set at 0.01 and the confinement factor was set at 1 . Moreover, dispersibility was not considered since the phosphate rock storehouse was the location for the airborne particulate sampling, where there was no cutting or grinding. When the dose was estimated considering the estimated intake and the ALI for each nuclide, the resulting value exceeded $0.3 \mathrm{mSv}$.

At the worksite mentioned above, the surveyed AMAD was $5.23 \mu \mathrm{m}$, the GSD was 1.7 , the density was $3.1 \mathrm{~g} \cdot \mathrm{cm}^{-3}$, and the shape factor was 1 . Since workers wore dust masks while carrying out operations, this was taken into account when conducting the dose assessment. The resulting value of the internal dose assessment was $0.16 \mathrm{mSv}$, which corresponds to level 1 . Therefore, if the current work environment is maintained, the radiological risk due to internal exposure is insignificant. However, protection measures, such as dust masks, are needed for protection of the respiratory organs. In 
addition, improvements should be identified through equipment inspection, since there is a likelihood that the dose may exceed $0.3 \mathrm{mSv}$ (the dose limit value). Continuous management of radiation dose is needed for workers through monthly or quarterly dose assessments, depending on the evaluator's judgment.

\section{3) Industries that handle monazite}

The industries selected in this study that handle monazite stored approximately $8,000 \mathrm{~kg}$ of monazite. The radioactivity concentrations for the ${ }^{238} \mathrm{U}$ decay series and ${ }^{232} \mathrm{Th}$ decay series nuclides of the monazite were $21,400 \mathrm{~Bq} \cdot \mathrm{kg}^{-1}$ and 213,000 $\mathrm{Bq} \cdot \mathrm{kg}^{-1}$, respectively. The need for particulate sampling was determined by examining the intake of monazite materials and the ALI of the key nuclides were selected. The release fraction was set at 0.01 and the confinement factor was set at 1. Moreover, dispersibility was considered to be 10 , since the monazite grinding dismantlement area was the location for the airborne particulate sampling, where there was cutting and grinding. When the dose was estimated considering the estimated intake and the ALI for each nuclide, the resulting value exceeded $0.3 \mathrm{mSv}$.

At the worksite mentioned above, the characteristics of airborne particulates were surveyed in seven different processing areas. In the said processing areas, the surveyed AMAD was 4.4-16 $\mu \mathrm{m}$, the GSD was 3.4-7.7, the density was 2.7-5.1 $\mathrm{g} \cdot \mathrm{cm}^{-3}$, and the shape factor was 1 . Since workers wore dust masks while carrying out operations, this was taken into account when conducting the dose assessment. The resulting value of the internal dose assessment was a maximum of $0.38 \mathrm{mSv}$ annually, which corresponds to level 2 . Therefore, the worksite must be improved by inspecting the equipment of the facilities and work methods. In addition, working hours must be adjusted, appropriate protection gear must be provided, and the radiation dose must be managed through continuous monitoring.

\section{Conclusion}

In this study, an internal dose assessment procedure was developed based on airborne particulate sampling in order to conduct a precise and consistent internal dose assessment for workers in industries that handle raw materials containing naturally occurring radioactive nuclides. The developed procedure was then applied to actual South Korean industries and the internal dose of the industries was assessed.
The internal dose assessment procedure is composed of determining the need for dose assessment, preliminary dose estimation, determining the need for particulate sampling, airborne particulate sampling and characterization, and assessment of radiation dose. The preliminary dose estimation was performed using the ALI of the ${ }^{40} \mathrm{~K}$ nuclide and the key nuclides of the ${ }^{238} \mathrm{U}$ decay series and ${ }^{232} \mathrm{Th}$ decay series, which affect the internal dose. The estimated radiation dose was categorized into three intervals (less than $0.1 \mathrm{mSv}, 0.1-0.3$ $\mathrm{mSv}$, greater than $0.3 \mathrm{mSv}$ ). Based on these intervals, the internal dose was assessed by carrying out airborne particulate sampling. The final internal dose assessment results were divided into level 0 (less than $0.1 \mathrm{mSv}$ ), level 1 (0.1-0.3 mSv), level 2 (0.3-1 mSv), and level 3 (greater than $1 \mathrm{mSv}$ ) in order to recommend appropriate radiation protection measures to abide by according to each level. To guarantee radiological safety for workers in areas where radiation levels are high, installations such as ventilators must be prepared, workers must be educated about radiological safety, protective gear must be worn, and safety measures depending on work patterns are needed.

The developed internal dose assessment procedure was applied to South Korea's representative industries that handle NORM, such as industries that handle coal, phosphate rock, and monazite. The industries were classified into the following levels: 0 for coal, 1 for phosphate rock, and 2 for monazite. This study recommended that radiation dose should be managed according to the dose levels by inspection and improvement of facility equipment and work methods, adjustment of working hours, and providing appropriate protective gear.

The internal dose assessment procedure developed in this study aims to provide consistent dose assessment results for industries that handle raw materials and contributes to the procurement of ALARA.

\section{Acknowledgements}

This work was supported by a grant from "Establishment of Technical Basis for Implementation on Safety Management for Radiation in the Natural Environment" carried out by Korea Institute of Nuclear Safety.

\section{References}

1. International Atomic Energy Agency. Assessing the need for ra- 
diation protection measures in work involving minerals and raw materials. IAEA Safety Report Series No 49. 2006;11-26.

2. International Atomic Energy Agency. Radiation protection and NORM residue management in the zircon and zirconia industries. IAEA Safety Reports Series No 51. 2007;51-61.

3. International Atomic Energy Agency. Radiation Protection and NORM Residue Management in the Production of Rare Earths from Thorium Containing Minerals. IAEA Safety Reports Series No 68. 2011;97-112.

4. International Atomic Energy Agency. Radiation protection and NORM residue management in the titanium dioxide and related industries. IAEA Safety Reports Series No 76. 2012;62-74.

5. Van der steen J, Timmermans CWM, Van Weer AW, Degrange JP, Lefaure C, Shaw PV. Strategies and methods for optimisation of protection against internal exposures of workers from industrial natural sources (SMOPIE). NRG report 20790. 2004;13-20.

6. Kim KP, Wu CY, Birky BK, Bolch WE. TENORM aerosols in the Florida phosphate industry assessment of lung fluid solubility and annual effective dose to workers. Radiat Prot Dosim. 2007; 123(1):41-55.

7. Florida Industrial and Phosphate Research Institute. Characterization of objects contaminated by technological enhanced naturally occuring radioactive materials (TENORM) within the phosphate industry. FIPR Publication No. 05-059-191. 2001;921.

8. Roper AR, Stabin MG, Delapp RC, Kosson DS. Analysis of naturally occurring radionuclides in coal combustion fly ash, gymsum, and scrubber residue samples. Health Phys. 2013;104(3): 264-269.
9. European Radiation Dosimetry Group. IDEAS Guidelines for the estimation of committed doses from incorporation monitoring data. EURADOS Report 2013-01. 2013;1-22.

10. United States Nuclear Regulatory Commission. Air sampling in the workplace. U.S. NRC Regulatory Guide 8.25. 1992;1-9.

11. International Atomic Energy Agency. Application of the concepts of exclusion, exemption and clearance. IAEA Safety Standards Series No RS-G-1.7. 2004;7-11.

12. United States Nuclear Regulatory Commission. Air sampling in the workplace. U.S. NRC NUREG-1400. 1993;1-4.

13. Japan Ministry of Education, Culture, Sports, Science and Technology. Guideline for Ensuring Safety of Raw Materials and Products Containing Uranium or Thorium. 2009;11-13.

14. International Commission on Radiological Protection. Human respiratory tract model for radiological protection. ICRP Publication 66. 1994;75-77.

15. International Atomic Energy Agency. Radiation protection and safety of radiation sources: international basic safety standards. IAEA Safety Standards Series GSR part 3. 2014;29-30.

16. International Commission on Radiological Protection. The 2007 recommendations of the International Commission on Radiological Protection. ICRP Publication 103. 2007;104-118.

17. Hinds WC. Aerosol technology: properties, behavior, and measurement of airborne particulates. 2nd Ed. New York NY. John Wiley \& Sons Inc. 1999;8-10.

18. Marshall M, Stevens DC. The purposes, methods and accuracy of sampling for airborne particulate radioactive materials. Health Phys. 1980;39(3):409-423. 